\title{
INSIGHT INTO HOSPITAL WARD NURSES' CONCERNS ABOUT PATIENT HEALTH AND THE CORRESPONDING MEDICAL EMERGENCY TEAM NURSE RESPONSE
}

Jaana Kalliokoski ${ }^{\mathrm{a}, *}$, Helvi Kyngäs ${ }^{\mathrm{b}}$, Tero Ala-Kokko ${ }^{\mathrm{c}}$, Merja Meriläinen ${ }^{\mathrm{c}}$

aCU, Vaasa Central Hospital, Hietalahdenkatu 2-4, FIN- 65130 Vaasa, Finland

${ }^{b}$ Research Unit of Nursing Science and Health Management, PL 5000, FIN- 90014 University of Oulu, Finland

${ }^{c}$ Division of Intensive Care Medicine, Department of Anesthesiology, PL 10, FIN- 90029 Oulu University Hospital, Finland

${ }^{*}$ Corresponding author. Tel.: +358 503091165.

E-mail addresses: jaana.kalliokoski@vshp.fi (J. Kalliokoski), helvi.kyngas@oulu.fi (H. Kyngäs), tero.ala-kokko@ppshp.fi (T. Ala-Kokko), merja.merilainen@ppshp.fi (M. Meriläinen).

Conflicts of interest: None

Funding sources: This research did not receive any specific grant from funding agencies in the public, commercial, or not-for-profit sectors.

Ethical approval details: World Medical Association Declaration of Helsinki (2013), Permission 217/2017. 


\section{TABLE OF CONTENTS}

ABSTRACT




\begin{abstract}
Aim: This study aims to understand the concerns of nurses when making MET calls which did not fulfil the vital sign criteria, and the MET nurses subsequent responses to these calls.

Methods: This was a retrospective report-based study. Research material included nursing reports and MET forms related to MET calls made due to nurses' concern. Inductive content analysis was used to identify observations, which were then quantified based on the research material.

Findings: From a total of 546 MET calls, 39 visits (7\%) were due to nurses' concern. In these 39 visits, the vital sign criteria did not reach the alert threshold, but nurses made the call due to subjective worry. In $13 \%$ of visits, the alert concern was inadequate contact with the doctor. MET nurses responded to the alert by providing clinical and indirect nursing; more specifically, they performed examinations and nursing interventions and collaborated with other professionals.

Conclusion: A nurse's worry is influenced by subjective changes in the patient's condition or an inadequate doctor's response rather than objective physiological measurements. A MET nurse's ability to assess patient condition, respond to nurses' calls, and acknowledge justified alerts help MET nurses support concerned nurses and encourage them to contact the MET if necessary.
\end{abstract}

Keywords: Critical Care Outreach Team, Emergency response team calling criteria, Medical Emergency Team, Nurses, Rapid Response Team, Vital signs, Worry

\title{
Implication for Clinical practice
}

- The findings suggest that the education of nurses that work outside of intensive care should also include an introduction to physiological measurements that are recorded in NEWS scores.

- Although MET nurses serve as an important link between ward nurses and the department doctors, and can help to translate subjective worries into objective clinical measurements it cannot be a service covering lack of response own department team. 
- There is room for improvement in the interdisciplinary cooperation at hospitals including education, guidelines and care processes regarding the ward patients. 


\section{INTRODUCTION}

In a hospital's general ward, patients can show changes in vital signs hours before cardiac arrest (Hillman et al., 2014; Jones et al., 2011). The Rapid Response System (RRS) was implemented in Australia in the early 1990s so that emergency teams could assess the deterioration of a patient. Certain criteria were developed to minimize the amount of unnecessary alerts. The success of RRS responses lies in early reaction to a patient's deterioration and the timely alerting of the emergency team (Hart et al., 2016; Jones et al., 2011). In this study, we use the term Medical Emergency Team (MET), which is synonymous with the concepts of Critical Care Outreach Team (CCOT) and Rapid Response Team (RRT) (Jones et al., 2009a; Tirkkonen, 2015).

MET calling criteria can be diverse. This study focusses on a hospital which uses the National Early Warning Score (NEWS) in MET calls. NEWS is a validated instrument (Bein et al., 2016) that compiles data covering different vital signs. Once the score exceeds the alert limit, the MET is called to assess the patient's condition (Tirkkonen, 2015). The objective criteria underlying a MET call are deterioration in some or all of the vital signs, namely, heart rate (HR), blood pressure (BP), oxygen saturation $(\mathrm{SaO} 2)$, respiratory rate (RR) and level of consciousness. In addition, a nurse's worry about a patient's deterioration can trigger a MET call even when vital sign criteria are not fulfilled (Gao et al., 2007; Jones et al., 2009a; Jones et al., 2011). According to Robert (2013), a basis for worry can be the nurse's intuition of the patient's deterioration. A nurse's intuition comprises multiple concepts, such as the nurse's objective observations and visual assessments of the patient's condition along with their subjective assessment of the patient's wellbeing (Robert, 2013).

The use of alert criteria in the monitoring of a patient's condition does not come without problems. For example, the nursing staff's understanding of the criteria and changes in patient condition can be insufficient (Donohue \& Endacott, 2010; Jones et al., 2009b). Also, the high workload of nursing staff can impair their monitoring of vital signs, as well as the reaction to any changes in the measurements (Jones et al., 2009b). The MET nurse's response to the objective alert criteria comprises both technical (e.g. airway inhalation 
and IV medication administration) and non-technical (e.g. example communication and education) activities (Topple et al., 2016). However, the reasons for ward nurses' worry, as well as the MET nurses' responses to calls caused by worry, have only received limited research attention.

The research covering MET nursing is still incomplete (Hovila et al., 2013; Topple et al., 2016). For example, the MET nurse job description has been compared to the activities of a wide range of healthcare roles: ICU Liaison Nurse/Outreach Service; patient care; personnel support; and teamwork with other professionals (Endacott \& Chaboyer, 2006). A part of MET research has focussed on the factors that encourage and impede MET calls. Good collaboration between the MET and different departments as well as trust in the MET's ability to help with patients outside of the ICU have been identified as factors that sustain MET activities (Jones et al., 2009b). In contrast, factors such as a negative relationship between the MET and ward staff (Jones et al., 2009b), fear of criticism due to an incorrect call, and uncertainty about breaching the existing hierarchical operating model by calling the MET before calling the department's own doctor can harm the functioning of a MET (Bagshaw et al., 2010).

The MET nurse's task partly depends on hospital culture. In this way, understanding the local culture precedes improvements to MET nursing and education (Santiano et al., 2011). This study concentrates on acute care unit (ACU) nurses' worry about a patient's deterioration along with how MET nurses respond to this concern at a University Hospital (UH). The paper defines ACU as an in-hospital setting in which patients receive noncritical care. 


\section{METHODS}

\section{Objectives}

This study aims to understand the concerns of nurses when making MET calls which did not fulfil the vital sign criteria, and the MET nurses subsequent responses to these calls. The knowledge can be used to further develop of the nursing of critically ill patient outside of intensive care unit by understanding ward nurses needs for education on how to react to patient's deterioration and develop MET nurses work so that they can support ward nurses to make MET alerts in time.

\section{Design}

The presented research was a retrospective report-based study. The studied data included electronic medical reports (EMR) and MET forms written by the acute care unit ACU nurse or MET nurse between 18.4.2016-17.4.2017. The presented research used mixed methods, namely, qualitative and quantitative content analysis.

\section{Setting and participants}

The study was performed at a UH which has 615 beds and 45373 (year 2017) annual ward admissions. This hospital introduced a MET pilot study in 2013 and established the first MET on 18.4.2016.

The primary MET response is performed by experienced ICU nurses who have completed MET training, with an intensivist as the consulting physician. There are a total of 141 trained MET nurses who work in three shifts to provide 24/7 service.

\section{Ethical approval}

The study was conducted with good scientific practice and research ethics principles according to the World Medical Association Declaration of Helsinki (2013). The study was approved by the hospital district medical director (Permission, 217/2017). Ethics committee approval was not required as this was a registered study, as such, any specific information regarding individuals will not be published and the researchers did not have any contact with the studied individuals. The documents included in this study were 
differentiated from each other with numbers; hence, the patients and nurses cannot be identified based on the reports they wrote (European Union, 2016; HE 9/2018, 2018).

\section{Data collection}

Purposive sampling was used to obtain the research material. The sampling process is illustrated in Figure 1. All MET calls and records were inspected by one of the authors (KJ) and only MET alerts for which ward nurses' worry was the reason for the call were included in the analyses. If a MET call was made several times for the same patient, the research only analysed the first call.

The hospital uses NEWS measurements as criteria for MET calls. MET calls are triggered when the total NEWS exceeds five points, when one objective NEWS parameter reaches five points, or in case of ward nurses' worry.

\section{Data analysis}

The narrative material from the MET forms and EMRs was analysed by inductive content analysis. This methodology was chosen because no previous theory or analytical frameworks were available for the researched subject, as the work of MET nurses has not been studied to a large extent (Elo \& Kyngäs, 2008). In addition to a qualitative analysis, the findings were quantified, with the overarching goal of understanding the reasons for nurses' worry and the subsequent MET nurse actions (Sormunen et al., 2013). The research material, i.e. the original material on MET forms and EMRs, was read multiple times. First, the ACU nurse's text was read so that the source of concern could be understood. The MET nurse's text was then read to gain an overall picture of the event. The EMRs written by nurses were later gathered and rewritten in a Word document. The text was saved in the OpenCode program as two separate files: one from the point of view of the concerned nurse and the other from the point of view of the responding MET nurse (OpenCode 4.03 program http://www.phmed.umu.se/english/units/epidemiology/research/open-code/).

The data were screened for answers to the research questions, namely, reasons for ward nurses' worry and MET nurses' responses. The data were processed in two groups; one group adopted the ACU nurse's perspective (Table 1) while the other adopted the MET 
nurse's perspective (Table 2). The analysis focussed on the composition of the text, and the analysis units were words, sentences or concepts (Graneheim \& Lundman, 2004). The text was reduced, and the identified expressions were coded with descriptive explanations as well as quantified. The coded expressions were grouped and divided into subcategories according to their content. Subcategories with similar content were further integrated into generic and main categories which reflected the research questions (Elo \& Kyngäs, 2008). Analysis were made by one of the authors $(\mathrm{KJ})$. Regular discussions were held with research groups via meetings and email in order to review both the analysis and the codes and categories to confirm the dependability of the analysis. 


\section{FINDINGS}

From the MET calls studied, seven percent arose from ward nurses' worry. MET calls with the "nurses worry" criteria were made by 37 nurses and two radiographers. The calls originated from different departments, but came mainly from surgery departments (Figure 2).

Information regarding the demographic characteristics of patients that were the subject of MET calls is presented in table 3. Seven patients were on their first day of treatment, 27 patients had been in the same department for the last 48 hours, and 12 patients had recently changed location, having been in ICU, surgery or emergency before the MET call. In 34 cases the patient remained in the same ward following the MET call, while two patients were transferred to the high dependency unit (HDU), two were transferred to the ICU and one patient was transferred from the X-ray department to the ward after the MET call.

\section{Factors which induce nurses' worry}

Two main categories of ward nurses' worry were identified: worry associated with the patient and worry associated with the organisation of work (Table 4).

Nurses' worry associated with the patient

Changes in the vital signs were the main reason for ward nurses' worry, underlying 21 MET calls. Concern linked to breathing (17 patients) included the mechanics of breathing, breathing sound, as well as oxygen saturation (SpO2). Aspiration was also considered as a breathing problem even though it could also have been considered an unexpected trajectory. Concerns linked to circulation included BP and HR problems, sweating, changes in skin colour or cold periphery. BP and HR problems appeared in 15 MET calls, with the values ranging from low or high, but not fulfilling the NEWS alert criteria. Changes in the patient's body temperature could also cause a nurse to worry. Increased body temperature was mentioned together with blood transfusions, hypoglycaemia, agitation, vomiting, and weariness. ACU nurses were worried about diuresis with nine patients. Problems with diuresis occurred in addition to other concerns. Also in nine cases, the patient's neurological status - agitation, aggression, resisting treatment, altered level 
of consciousness - was the reason for the MET call. In this research, agitation was categorized as an unexpected event.

Unexpected trajectory included the previously mentioned agitation, along with complications, spasms, syncope, abdominal distress and unstable blood glucose. Complications included bleeding and problems with invasive medical devices. Abdominal distress covered any complications in the abdominal region, such as nausea and vomiting, intestinal bleeding and distended abdomen. A patient's collapse or dizziness were classed as a temporary decline in the level of consciousness.

The patient's own subjective sensations, for example, pain, feeling unwell, dissatisfaction of their own state, or concern for their own health, concerned the ACU nurses. Pain was one of the most common causes of worry, as this was mentioned in 18 MET calls. Pain was usually reported with other causes for concern. It could be listed in connection with the patient's general illness, or could be more spontaneous, for example, clinical signs are fine, but the patient is restless and ill.

The nurse's subjective reasons for concern were quite vague as they were not accurately expressed. The patient's tiredness was often at the root of the subjective concern, but it was difficult to determine whether the concern regarded the patient's holistic exhaustion or absence of strength from the nurses' text. The nurses also called a MET nurse to examine the situation if they had difficulties getting an overall picture of the patient's different problems. The nurse may have already taken care of the situation but nevertheless wants a MET nurse to check the patient.

Nurses' worry associated with the organisation of work

Ward nurses' worry also includes an organisational perspective. For example, a MET nurse is called for help if the nurse is not receiving adequate support from the doctor or if more staff are needed for the patient's treatment. The ward nurse may make a MET call instead of, or in addition to, requesting a doctor when the doctor is busy elsewhere, it is unclear which doctor is in charge, or the ACU nurse wants a MET nurse to help contact the doctor. Moreover, the nurse may contact the MET if they feel that the doctor's instructions are inadequate. 


\section{MET nurses' responses to the call}

The MET nurses' responses were separated into two main categories: MET nurses' immediate nursing activities (i.e. clinical nursing) and MET nurses' indirect nursing activities.

\section{Clinical nursing}

The patient's examination includes that the MET nurse checks the vital signs, diuresis and level of pain. The nurse checked the vital signs either by calculating the NEWS (23 patients) or as separate observations of respiration, blood circulation, and/or level of consciousness. The MET nurse evaluated the respiratory sign of 33 patients. They examined this by the patient's breathing sounds, whether or not breathing was laboured, and if breathing affected the patient's speech. The MET nurse assessed circulation by HR, BP, periphery status or the patient's skin colour. The level of consciousness was evaluated in 35 patients. The nurse performed this assessment by communication, with consciousness expressed verbally either through the Glasgow Coma Scale (GCS) or NEWS. Urinary retention can trigger a MET call even if it is not included in the NEWS. The MET nurse checked the patient's diuresis through urine quantity, colour and/or potential oedema. Upon the MET nurse's arrival, pain was assessed in 17 patients, with 11 presenting pain. The nurse estimated the patient's pain, or lack thereof, according to the patient's statements or health condition.

The MET nurse communicated with the patient by conversation, support and guidance during almost every MET call. The discussions they had with the patients regarded current situation, and support was either a calming presence or verbal support. Guidance, on the other hand, was meant to motivate the patient to help them take care of themselves.

When contributing to EMRs, the MET nurse paid particular attention to the patients' previous examinations (e.g. laboratory values or radiographies), prior treatments (e.g. respiratory or pharmacological therapy), as well as the current treatment's limits. Some of the observations compensate for the anaesthetist consultation.

The MET nurses' nursing interventions included body positioning and respiratory therapy, and were provided to 19 patients. The patient's pain medication, fluids and other 
drug therapies were modified or started according to the doctor's instructions in seven cases. Other nursing interventions included assisting in the transfer of patients, rinsing the catheter, and treatment of complications arising from medical devices.

\section{Indirect nursing}

The MET nurse guided the staff in the monitoring of vital signs, BP, diuresis and body temperature. She counselled the staff in how to administer drug and fluid therapy, as well as how to provide respiratory and body positioning therapies. The MET nurse also suggested that the physician should be consulted for treatment instruction unless the patient has a critical problem.

The organisation of MET work starts and depends on the incoming MET call. First, the MET nurse prepares for the visit by reviewing the medical history obtained from the ACU nurse. The MET evaluation provides the ward nurses with instructions for how to continue patient care. The last phase is the planning of a follow-up visit. The MET nurse either decides alone, or by requesting the anaesthetist's professional opinion, whether a follow-up visit will be required.

Multiprofessional collaboration was identified to be a part of the MET nurses' activities. The nurse acted as an expert or consultant when ward nurses could not reach the doctor, as an intermediary between the ward nurse and doctor, and vice versa, or as a partner to the anaesthetist. Discussions between the MET nurse and the nursing staff focussed on the patient's condition and its changes. The conversation also considered the nurse's worry and possible consultations with the doctor. The MET nurse supported the alerting nurse's work; for example, they would encourage the ward nurse to contact the MET again if the patient's condition deteriorates. The MET nurse encouraged the ward nurse to initiate another MET call at almost every visit, exceptions being if the patient was moved elsewhere for treatment, the nurse had already planned another visit, if the patient's condition had improved, or if the doctor had prescribed treatments or medical examinations.

Table 6 provides direct quotes from data that exemplify categories within ACU nurses' worry and MET nurses' response. 


\section{DISCUSSION}

To the best of our knowledge, this is the first report-based study that investigated ward nurses' worry as a reason for MET calls and the MET nurses' responses to these types of calls. This study unearthed several important findings. First, ward nurses' worry has two origins: the perspective of the patient and the organisation of work. The ACU nurses were concerned about a patient's condition and alerted MET before objective measurements reached MET calling criteria. The organisational perspective was dominated by inadequate contact with the doctor, and, for this reason, ward nurses decided to call the MET. Furthermore, the MET nurses' responses could be separated into two perspectives, namely, clinical nursing focussed on the patients' vital signs whereas indirect nursing encompassed interdisciplinary collaboration actions, for example, positive communication with the worried nurse. In addition, we noticed that ward nurses do not use objective measurements like the GCS, NEWS or VAS.

In our study, less than 10 per cent of the MET calls were related to ward nurses' worry. Results from previous studies have indicated that $11-41 \%$ of MET calls are triggered by nurses' worry (Chen et al., 2010; Douw et al., 2018; Hodgetts et al., 2002; Parr et al., 2001; Santiano et al., 2009). However, from 2000-2012, MET calls due to nurses' worry have decreased whereas calls supported by objective measurements have increased (Herod et al., 2014). This trend supports our result of fewer worry-related MET calls. It can be presumed that these changes in MET calls are due to improvements in monitoring (Evans, 2015; Herod et al., 2014) as well as a "Between the Flags" system which authorises triggering the MET system according to a scale that considers both vital signs and the nurse's worry (Chen et al., 2016).

A nurse's worry was described as subjective in our study, as the objective measurements would more accurately reflect the patient's situation. Previous research has found that MET calls are rarely made based on RR measurements (Chen et al., 2009; Cretikos et al., 2008; Herod et al., 2014; Hillman et al., 2014); a similar result was found in this study, as the studied ACU nurses did not measure the patient's RR. It assumed that reliance on electronic monitoring has decreased the need to use visual methods for supervising patient $\mathrm{RR}$, while electronic monitoring improves the tracking of other vital signs (Chen et al., 
2009). Instead of the objective VAS, nurses verbally described the quality or quantity of pain. The VAS was only used once, although several patients experienced pain. The result was the same for GSC, as none of ACU nurses used the objective GCS measurement, but rather described changes in consciousness verbally. Only once ACU nurse calculated the NEWS, but the marking was perhaps a mistake because only values describing consciousness were found in the EMR. By comparison, the MET nurse calculated quite high NEWS, even though the alerting nurse did not notice the NEWS at all. Workload can undermine the use of the objective measuring tools (Jones et al., 2009b), as NEWS measurements require time and resources from the nurse (Bein et al., 2016; Jonsson et al., 2011). Nevertheless, monitoring vital signs is often better than documentation (Jonsson et al., 2011).

The factors influencing ward nurses' worry identified in the presented study were similar to what has previously been reported. The validated "changes of concern" (Cioffi et al., 2010) and ten indicators reflecting the nature of a nurse's worry (Douw et al., 2015) describe, for example, changes in breathing, circulation, consciousness, pain level, and the nurse's or patient's indefinable concern. Researchers have highlighted the importance of the concern criterion as well as a nurse's intuition in both reacting to the patient's deterioration (Douw et al., 2015) as a part of the decision-making before the MET call (Cioffi et al., 2010) and at encouraging communication in professional groups (Lavoie et al., 2016; Santiano et al., 2009).

It is possible to notice changes in a patient's condition before any objective values have been obtained (Douw et al., 2015; Douw et al., 2018), and measuring vital signs should be the minimum requirement in tracking the deterioration of patient condition (Smith et al., 2013). In this study, $48 \%$ of the nurses' worry stemmed from subjective changes in the patients' vital signs. In this way, the decision to make a MET call was based on the nurse's subjective assessment of the changes in a patient's condition relative to a previous situation. Similarly, $43 \%$ of the MET nurses' responses were related to the patient's vital signs. Topple et al. (2016) provided comparable results, finding that MET nurses actions reflected the reason of the MET call. Furthermore, Santiano et al. (2011) found that MET nurses use almost half of the alarm time to evaluate the patient's status and treatment needs. 
In this research, MET nurses used objective measurements and performed observations, nursing and communication with other professionals. According to Lavoie et al. (2016), ICU nurses favour numeric measurements because the intensivists find objective measurements more appropriate. Nevertheless, subjective nurse's concern remains an acceptable MET call criterion (Santiano et al., 2009). The decision to rely on objective or subjective observations is the significant difference between ICU and ACU nurses (Lavoie et al., 2016).

The activation of the MET alert can sometimes be difficult even if the patient exhibits clear changes in vital signs and the nurse is worried about the patient's health (Braaten, 2015). For example, it can be hard to justify an alert before the objective criteria are fulfilled (Braaten, 2015; McGaughey et al., 2017). It is possible to increase early phase MET calls by communicating the justifications for MET alerts (Shapiro et al., 2010), multiprofessional cooperation (Braaten, 2015), understanding the hospital culture and improving the MET education (McGaughey et al., 2017). Positive experiences with MET calls will encourage nurses to use their intuition and voice their concern more often (Robert, 2013).

In this study, the MET nurses supported the ward nurses' MET decision-making and legitimised the decision to alert the MET system for almost every call. Collaborative problem-solving with the MET nurse strengthens the ACU nurse's feeling of autonomy and adds knowledge on the patient's situation (Shapiro et al., 2010; Williams et al., 2011). A lack of communication between the ACU nursing staff and physicians and/or anaesthetists can also increase MET calls (Braaten, 2015); in these cases, the MET nurse can act as a communication channel (Topple et al., 2016) and maintain communication between nurses and doctors (Endacott et al., 2009).

\section{Reliability of the study}

Reliability was assessed during the research process; more specifically, reliability was evaluated through the criteria of credibility, transferability, dependability and confirmability (Lincoln \& Guba, 1985). To ensure credibility, the results of the study were reported carefully, and original quotations were used to authenticate the results. Transferability was ensured by carefully describing the research materials so that the 
reader could deduce how to use the results for further research (Graneheim \& Lundman, 2004). Dependability was strengthened and considered by discussing choices within the research group and pondering the results with MET nurses from other organisation. Sometimes it is recommended that the analysis be performed by more than one person to increase the comprehensivity and provide sound interpretation of the data (Burla et al., 2009). However, this includes many risks because both researchers always look at the data from their own perspectives. That is why the dialogue among co-researchers who are familiar with the topic of the research is beneficial matter of the research is useful. That dialogue is based on the analysis path indicated in table. Based on that co-authors can evaluate how the analysis is done and categories is formatted and comment on whether the findings are justified (Graneheim \& Lundman, 2004; Elo et al., 2014). Confirmability was reached by comparing results to what has been reported in previously published research. From the point of view of practical utilisation, the quantification of the results strengthens our claims that certain points, such as the importance of nurses' intuition, should be emphasised in MET education.

The small size of the materials used in qualitative research can reduce the reliability of a study. However, as the presented results were saturated and no new information could be extracted, it can be deduced that the data amount underlying this research was appropriate. The limit of research relying on a retrospective registry is that the data already exists, and no new data can be added. This research investigated nurses' narratives during MET calls. The text was partly unsystematic and not in chronological order, both of which may have affected the analysis and interpretation of the results. The fact that this research studied a sequential process of two phases, that is, an ACU nurse's worry, which was then answered by the MET nurse's response, added to the reliability. Furthermore, the study's reliability was strengthened by the objective analysis of the nurses' writing rather than an interpretation of other possible meanings. 


\section{CONCLUSION}

Ward nurse use their tacit knowledge of a patient's deterioration to trigger the MET system using the nurse's worry criterion before the objective MET call criteria are fulfilled. This means that they do not use the objective GCS, NEWS and VAS indicators to describe the patient's condition and communicate the patient's status.

In contrast, MET nurses estimate the patient's condition using objective measurements and prevent the deterioration of the patient's condition either by actively participating or by instructing the ACU nurse to observe and treat the patient. The MET nurse acts as a communication channel, linking the ACU nurse and the doctor, and vice versa. A MET nurse's expertise in evaluating the patient's condition, responding to the nurse's worry, and legitimising MET calls can support and encourage early phase MET calls and collegial nursing decision-making.

This study demonstrates that staff outside of the ICU should be educated in using the NEWS criteria to recognise critically ill patients. Furthermore, the findings stress that interdisciplinary communication in the hospital setting, especially between departments, must be improved. Further research could develop a computer-based questionnaire for evaluating the extent that healthcare professionals use objective measurements in their day-to-day work and provide simulation exercises that would improve interdisciplinary cooperation. 


\section{REFERENCES}

Bagshaw, S.M., Mondor, E.E., Scouten, C., Montgomery, C., Slater-MacLean, L., Jones, D.A., Bellomo, R., Gibney, N.R.T., for the Capital Health Medical Emergency Team Investigators, 2010. A Survey of Nurses' Beliefs About the Medical Emergency Team System in a Canadian Tertiary Hospital. Am J Crit Care 19(1): 74-83.

Bein, B., Seewald, S., Gräsner, J., 2016. How to avoid catastrophic events on the ward. Best Practice \& Research Clinical Anaesthesiology 30(2): 237-245.

Braaten, J.S., 2015. Hospital system barriers to rapid response team activation: A cognitive work analysis. Am J Nurs 115(2): 22-32.

Burla, L., Knierim, B., Barth, K. L., Duetz, M., Abel, T., 2008. From the text to coding: Intercoder reliability assessment in qualitative content analysis. Nurs Res 57, 113117.

Chen, J., Bellomo, R., Hillman, K., Flabouris, A., Finfer, S., 2010. Triggers for emergency team activation: A multicenter assessment. J Crit Care 25(2): 359.e1359.e7.

Chen, J., Ou, L., Flabouris, A., Hillman, K., Bellomo, R., Parr M., 2016. Impact of a standardized rapid response system on outcomes in a large healthcare jurisdiction. Resuscitation 107: 47-56.

Chen, J., Hillman, K., Bellomo, R., Flabouris, A., Finfer, S., Cretikos, M., MERIT Study Investigators for the Simpson Centre, ANZICS Clinical Trials Group, 2009. The impact of introducing medical emergency team system on the documentations of vital signs. Resuscitation 80(1): 35-43.

Cioffi, J., Conway, R., Everist, L., Scott J., Senior, J., 2010. 'Changes of concern' for detecting potential early clinical deterioration: a validation study. Aust Crit Care 23(4): 188-196.

Cretikos, M.A., Bellomo, R., Hillman, K., Chen, J., Finfer, S., Flabouris, A., 2008. Respiratory rate: The neglected vital sign. Retrieved from https://search.proquest.com/docview/235678699?accountid=13031. Med J Aust 188(11): 657-659.

Donohue, L.A., Endacott, R., 2010. Track, trigger and teamwork: Communication of deterioration in acute medical and surgical wards. Intensive Crit Care Nurs 26(1): $10-17$.

Douw, G., Huisman-de Waal, G., van Zanten, A.R.H., van der Hoeven, J.G., Schoonhoven, L., 2018. Surgical ward nurses' responses to worry: An observational descriptive study. Int J Nurs Stud 85: 90-95. 
Douw, G., Schoonhoven, L., Holwerda, T., Huisman-de Waal, G., van Zanten, A.R.H., van Achterberg, T., van der Hoeven, J.G., 2015. Nurses' worry or concern and early recognition of deteriorating patients on general wards in acute care hospitals: A systematic review. Crit Care 19(1).

Elo, S., Kyngäs, H., 2008. The qualitative content analysis process. Journal of Advanced Nursing 62(1): 107-115.

Elo, S., Kääriäinen, M., Kanste, O., Pölkki, T., Utriainen, K., Kyngäs, H., 2014. Qualitative content analysis: a focus on trustworthiness. SAGE open, 4(1) 2014: 110. DOI: $10.1177 / 2158244014522$

Endacott, R., Chaboyer, W., 2006. The nursing role in ICU outreach: an international exploratory study. Nurs Crit Care 11(2): 94-102.

Endacott, R., Eliott, S., Chaboyer, W., 2009. An integrative review and meta-synthesis of the scope and impact of intensive care liaison and outreach services. J Clin Nurs 18(23): 3225-3236.

European Union, 2016. GDPR. EUR-Lex REGULATION (EU) 2016/679 OF THE EUROPEAN PARLIAMENT AND OF THE COUNCIL, of 27 April 2016, on the protection of natural persons with regard to the processing of personal data and on the free movement of such data, and repealing Directive 95/46/EC (General Data Protection Regulation) http://data.europa.eu/eli/reg/2016/679/oj. Read 30.7.2018.

Evans, R.S., Kuttler, K.G., Simpson, K.J., Howe, S., Crossno, P.V., Johnson, K.V., Schreiner, M.N., Lloyd, J.F., Tettelbach, W.H., Keddington, R.K., Tanner, A., Wilde, C., Clemmer, T.P., 2015. Automated detection of physiologic deterioration in hospitalized patients. J Am Med Inform Assoc 22(2): 350-360.

Gao, H., McDonnell, A., Harrison, D.A., Moore, T., Adam, S., Daly, K., Esmonde, L., Goldhill, D.R., Parry, G.J., Rashidian, A., Subbe, C.P., Harvey, S., 2007. Systematic review and evaluation of physiological track and trigger warning systems for identifying at-risk patients on the ward. Intensive Care Med 33(4): 667-679.

Graneheim, U.H., Lundman, B., 2004. Qualitative content analysis in nursing research: concepts, procedures and measures to achieve trustworthiness. Nurse Education Today 24(2): 105-112.

Hart, P.L., Spiva, L., Dolly, L., Lang-Coleman, K., Prince-Williams, N., 2016. Medicalsurgical nurses' experiences as first responders during deterioration events: a qualitative study. J Clin Nurs 25(21): 3241-3251.

HE 9/2018, 2018. Hallituksen esitys eduskunnalle EU:n yleistä tietosuoja-asetusta täydentäväksi

lainsäädännöksi. https://www.finlex.fi/fi/esitykset/he/2018/20180009. $\quad$ Read 30.7.2018. 
Herod, R., Frost, S.A., Parr, M., Hillman, K., Aneman, A., 2014. Long term trends in medical emergency team activations and Resuscitation 85(8): 1083-1087.

Hillman, K.M., Chen, J., Jones, D., 2014. Rapid response systems. Med J Aust 2014(9): 519-521.

Hodgetts, T.J., Kenward, G., Vlachonikolis, I.G., Payne, S., Castle, N., 2002. The identification of risk factors for cardiac arrest and formulation of activation criteria to alert a medical emergency team. Resuscitation 54(2): 125-131.

Hovila, S., Hopia, H., Kiuttu, T., Kivinen, T., 2013. Ennakoivan elvytystoiminnan tilanteet sairaalassa hoitohenkilöstön näkökulmasta. Tutkiva hoitotyö 11(4): 23-30.

Jones, D.A., DeVita, M.A., Bellomo, R., 2011. Rapid-response teams. N Engl J Med 365(2): 139-146.

Jones, D., Bellomo R., DeVita, M., 2009a. Effectiveness of the Medical Emergency Team: the importance of dose. Crit Care 13(5): 313.

Jones, L., King, L., Wilson, C., 2009b. A literature review: Factors that impact on nurses' effective use of the Medical Emergency Team (MET). J Clin Nurs 18(24): 33793390.

Jonsson, T., Jonsdottir, H., Möller, A.D., Baldursdottir, L., 2011. Nursing documentation prior to emergency admissions to the intensive care unit. Nurs Crit Care 16(4): 164169.

Lavoie, P., Pepin, J., Alderson, M., 2016. Defining patient deterioration through acute care and intensive care nurses' perspectives. Nurs Crit Care 21(2): 68-77.

Lincoln, $\quad$ Y., Guba, $\quad$ E., Naturalistic Inquiry. Newbury Park, CA, Sage.

McGaughey, J., O'Halloran, P., Porter, S., Blackwood, B., 2017. Early warning systems and rapid response to the deteriorating patient in hospital: A systematic realist review. J Adv Nurs 73(12): 2877-2891.

Parr, M.J.A., Hadfield, J.H., Flabouris, A., Bishop, G., Hillman, K., 2001. The Medical Emergency Team: 12 month analysis of reasons for activation, immediate outcome and not-for-resuscitation orders. Resuscitation 50(1): 39-44.

Robert, R.R., 2013. The role of intuition in nurses who activate the Rapid Response Team (RRT) in medical-surgical and telemetry units. A dissertation thesis. Denton, Texas, Texas Woman's University.

Santiano, N., Young, L., Baramy, L.S., Cabrera, R., May, E., Wegener, R., Butt, D., Parr, M., Armstrong, K., Brillante, V., Brennan, K., Chan, C., Clare, M., Curley, L., Hedges, S., Murphy, J., Nicholson, M., Parker, S., Shunker, S.A., Stevenson, J., 
Twadell, N., Sanchez, D., Sutevski, V., Quach, M., Whelan, M., 2011. The impact of the medical emergency team on the resuscitation practice of critical care nurses. BMJ Qual Saf 20(2): 115-120.

Santiano, N., Young, L., Hillman, K., Parr, M., Jayasinghe, S., Baramy, L., Stevenson, J., Heath, T., Chan, C., Claire, M., Hanger, G., 2009. Analysis of Medical Emergency Team calls comparing subjective to "objective" call criteria. Resuscitation 80(1): 4449.

Shapiro, S.E., Donaldson, N.E., Scott, M.B., 2010. Rapid response teams seen through the eyes of the nurse. Am J Nurs 110(6): 28-36.

Smith, G.B., Prytherch, D.R., Meredith, P., Schmidt, P.E., Featherstone, P.I., 2013. The ability of the National Early Warning Score (NEWS) to discriminate patients at risk of early cardiac arrest, unanticipated intensive care unit admission, and death. Resuscitation 84(4): 465-470.

Sormunen, M., Saaranen. T., Tossavainen, K., Turunen, H., 2013. Monimenetelmätutkimus terveystieteissä. Sosiaalilääketieteellinen aikakauslehti 50: 312-321.

Tirkkonen, J., 2015. Detecting and reacting to in-hospital patient deterioration: studies on the afferent and efferent limbs of the Rapid Response System. Väitöskirja. Acta Electronica Universitatis Tamperensis (1580).

Topple, M., Ryan, B., Baldwin, I., McKay, R., Blythe, D., Rogan, J., Radford, S., Jones, D., 2016. Tasks completed by nursing members of a teaching hospital Medical Emergency Team. Intensive Crit Care Nurs 32(1): 12-19.

Williams, D.J., Newman, A., Jones, C., Woodard, B., 2011. Nurses' perceptions of how rapid response teams affect the nurse, team, and system. J Nurs Care Qual 26(3): 265-272.

World Medical Association Declaration of Helsinki, 2013. Ethical principles for medical research involving human subjects. JAMA 310(20): 2191-2194. 


\section{ATTACHMENTS}

Table 1. An example of the analysis process regarding MET calls due to nurses' concern

\begin{tabular}{|c|c|c|}
\hline Meaning unit & Condensed meaning unit & Code \\
\hline $\begin{array}{l}\text { Breathing is not scratching, but it is } \\
\text { quite heavy. }\end{array}$ & Heavy breathing. & Difficulty breathing. \\
\hline Apnoea when he is sleeping. & Sleep apnoea. & \\
\hline $\begin{array}{l}\text { Periphery is cold, both hands and } \\
\text { legs. }\end{array}$ & Cold periphery. & Periphery temperature. \\
\hline $\mathrm{BP}$ is as high as earlier. & $\mathrm{BP}$ is high. & BP problems. \\
\hline $\begin{array}{l}\text { Called the MET nurse at noon, } \\
\text { because of worry about the } \\
\text { patient's deterioration. }\end{array}$ & $\begin{array}{l}\text { Nurse is worried about the } \\
\text { patient's deterioration. }\end{array}$ & $\begin{array}{l}\text { Nurse's worry about } \\
\text { patient. }\end{array}$ \\
\hline $\begin{array}{l}\text { We needed } 3-4 \text { nurses to hold } \\
\text { patient before the arrival of the } \\
\text { security guard. }\end{array}$ & Need for extra staff. & More staff is needed. \\
\hline $\begin{array}{l}\text { I called upon the MET nurse to } \\
\text { contact anaesthetist if necessary. }\end{array}$ & $\begin{array}{l}\text { MET nurse's support is needed to } \\
\text { communicate with the } \\
\text { anaesthetist. }\end{array}$ & $\begin{array}{l}\text { Nurse wants a MET nurse } \\
\text { to help contact the doctor. }\end{array}$ \\
\hline
\end{tabular}


Table 2. An example of the analysis process regarding MET nurses' responses

\begin{tabular}{lll}
\hline Meaning unit & Condensed meaning unit & Code \\
\hline $\begin{array}{l}\text { When MET nurse came in the } \\
\text { room, patient was awake and } \\
\text { makes sense. }\end{array}$ & Patient is awake and makes sense. & Assess GCS \\
$\begin{array}{l}\text { BP 214/120, HR 109. SpO2 } \\
98 \%, \text { breathing is quiet, } \mathrm{HF} \mathrm{16.}\end{array}$ & Observe vital signs \\
$\begin{array}{l}\text { Patient's abdomen feels tender. } \\
\text { The patient was advised to ring }\end{array}$ & Patient has pain. & Patient was advised to ask help. \\
the bell easily. & Support the patient. \\
$\begin{array}{l}\text { Instructed to easily contact } \\
\text { again, if the patient's state }\end{array}$ & New contact to MET, if necessary. & Support the alerting nurse. \\
worsens. & & \\
$\begin{array}{l}\text { The case was explained to the } \\
\text { anaesthetist afterwards... }\end{array}$ & $\begin{array}{l}\text { An anaesthetist has been informed } \\
\text { about the MET call. }\end{array}$ & $\begin{array}{l}\text { Consultation } \\
\text { anaesthetist }\end{array}$ \\
$\begin{array}{l}\text { Instructed to call to the treating } \\
\text { doctor if... }\end{array}$ & $\begin{array}{l}\text { Instructed to call the treating } \\
\text { doctor. }\end{array}$ & Staff guidance \\
\hline
\end{tabular}


Table 3. Characteristics of admitted patients

\begin{tabular}{|c|c|c|c|}
\hline Age (year) & Average of 68.3 & \multicolumn{2}{|c|}{ range $35-102$} \\
\hline Gender & Male 24 & \multicolumn{2}{|c|}{ Female 15} \\
\hline Elective / Emergency room patient & Elective 14 & \multicolumn{2}{|c|}{ Emergency room patient 25} \\
\hline $\begin{array}{l}\text { Hospital admission before MET call } \\
\text { (day) }\end{array}$ & Average of 6.9 & range & \\
\hline $\begin{array}{l}\text { Main reason for hospital admission, } \\
\text { number and percent }\end{array}$ & $\begin{array}{l}\text { Alimentary tract disorder } \\
\text { Cerebrovascular disorder } \\
\text { Surgical treatment } \\
\text { Sepsis } \\
\text { Others } \\
\text { Total }\end{array}$ & $\begin{array}{l}13 \\
4 \\
13 \\
3 \\
6 \\
39\end{array}$ & $\begin{array}{l}33 \% \\
10 \% \\
33 \% \\
8 \% \\
15 \%\end{array}$ \\
\hline $\begin{array}{l}\text { Number of chronic diagnosis / } \\
\text { patients } \\
\text { (Patient could have more than one } \\
\text { chronic diagnosis) }\end{array}$ & Average of 5.28 & range & \\
\hline $\begin{array}{l}\text { Number and percent of chronic } \\
\text { diagnosis }\end{array}$ & $\begin{array}{l}\text { Coronary artery disease } \\
\text { Hypertension } \\
\text { Other cardiovascular } \\
\text { diseases } \\
\text { COPD / Asthma } \\
\text { Other respiratory diseases } \\
\text { Diabetes type } 1 \text { / type } 2 \\
\text { Rheumatism } \\
\text { Chronic kidney disease } \\
\text { Chronic hepatic disease } \\
\text { Cerebrovascular disorder } \\
\text { Cancer tumour / blood } \\
\text { Other chronic disease } \\
\text { Total }\end{array}$ & $\begin{array}{l}12 \\
28 \\
23 \\
1 / 3 \\
3 \\
4 / 16 \\
5 \\
7 \\
4 \\
4 \\
25 / 3 \\
68 \\
206\end{array}$ & $\begin{array}{l}6 \% \\
13 \% \\
11 \% \\
1 \% / 2 \% \\
2 \% \\
2 \% / 8 \% \\
2 \% \\
3 \% \\
2 \% \\
2 \% \\
12 \% / 2 \% \\
33 \%\end{array}$ \\
\hline
\end{tabular}


Table 4. Factors which induce a nurse's concern

\begin{tabular}{|c|c|c|c|}
\hline & Categories & & \\
\hline Code & $\begin{array}{l}\text { Sub (number of } \\
\text { positive findings) }\end{array}$ & $\begin{array}{l}\text { Generic (\% of } \\
\text { positive findings) }\end{array}$ & Main \\
\hline $\begin{array}{l}\text { Gasping, aspiration, difficulty in breathing, } \\
\text { use of accessory muscle, apnoeic pause, } \\
\text { sliminess and noisy breathing (wheezing, } \\
\text { crackling). }\end{array}$ & Breathing 19 & \multirow{6}{*}{$\begin{array}{l}\text { Changes in the vital } \\
\text { signs } 48 \%\end{array}$} & \multirow{14}{*}{$\begin{array}{l}\text { Concern associated } \\
\text { with the patient } \\
94 \%\end{array}$} \\
\hline Fall of $\mathrm{SpO} 2$ and changing saturation. & $\mathrm{SpO} 210$ & & \\
\hline $\begin{array}{l}\text { Sweating, periphery temperature, } \mathrm{HR} \\
\text { problems, BP problems, shivering and } \\
\text { abnormal skin colour. }\end{array}$ & Circulation 33 & & \\
\hline Low-grade fever, chilling and rigoring. & $\begin{array}{l}\text { Body temperature } \\
\text { (Celsius degree) } 8\end{array}$ & & \\
\hline $\begin{array}{l}\text { Oedema and the colour or amount of urine } \\
\text { and problems with balance. }\end{array}$ & Diuresis 11 & & \\
\hline $\begin{array}{l}\text { Changes in the level of consciousness, } \\
\text { confusion, sleepiness, and lethargy. }\end{array}$ & $\begin{array}{l}\text { Neurological status } \\
5\end{array}$ & & \\
\hline $\begin{array}{l}\text { Nausea and vomiting, intestinal bleeding } \\
\text { and distended abdomen. }\end{array}$ & $\begin{array}{l}\text { Abdominal distress } \\
8\end{array}$ & \multirow{5}{*}{$\begin{array}{l}\text { Unexpected } \\
\text { trajectory } 22 \%\end{array}$} & \\
\hline $\begin{array}{l}\text { Aggressive, restless, and object to } \\
\text { treatment. }\end{array}$ & Agitation 17 & & \\
\hline $\begin{array}{l}\text { Bleeding and problems linked to invasive } \\
\text { medical devices. }\end{array}$ & Complications 18 & & \\
\hline Spasm & Spasms 2 & & \\
\hline Collapse or dizziness. & Syncope 2 & & \\
\hline Pain, chest pain and stomach-ache. & Pain 18 & \multirow{2}{*}{$\begin{array}{l}\text { Subjective } \\
\text { sensations of the } \\
\text { patient } 15 \%\end{array}$} & \\
\hline $\begin{array}{l}\text { Dissatisfaction of own state, feeling unwell } \\
\text { and concern for own health. }\end{array}$ & Feeling unwell 10 & & \\
\hline $\begin{array}{l}\text { Patient's tiredness, patient is weary, tired or } \\
\text { exhausted and nurse is concerned about } \\
\text { patient. }\end{array}$ & $\begin{array}{l}\text { Nurse observation } \\
16\end{array}$ & $\begin{array}{l}\text { Subjective concerns } \\
\text { of the nurse } 9 \%\end{array}$ & \\
\hline $\begin{array}{l}\text { Doctor is busy elsewhere and it is unclear } \\
\text { which doctor is in charge. } \\
\text { Nurse wants a MET nurse to help contact } \\
\text { the doctor or feels that doctor's instructions } \\
\text { are inadequate. }\end{array}$ & Medical staff 9 & & \multirow[t]{2}{*}{$\begin{array}{l}\text { Concern associated } \\
\text { with the } \\
\text { organisation of } \\
\text { work } 6 \%\end{array}$} \\
\hline More staff are needed. & Nursing staff 2 & & \\
\hline
\end{tabular}


Table 5. MET nurses' responses to the call

\begin{tabular}{|c|c|c|}
\hline \multirow[b]{2}{*}{ Code } & \multicolumn{2}{|l|}{ Categories } \\
\hline & $\begin{array}{l}\text { Sub (number of positive } \\
\text { findings) }\end{array}$ & $\begin{array}{l}\text { Main ( } \% \text { of positive } \\
\text { findings) }\end{array}$ \\
\hline $\begin{array}{l}\text { Perform ECG and assess GCS, clinically examine } \\
\text { breathing, SpO2, circulation, periphery circulation, } \\
\text { operative wound and blood glucose. } \\
\text { Observe pain, body temperature, fluid balance, skin } \\
\text { colour, and diuresis. Observe vital signs and physical } \\
\text { condition. }\end{array}$ & $\begin{array}{l}\text { The patient's } \\
\text { examination } 175\end{array}$ & \multirow{4}{*}{ Clinical nursing $63 \%$} \\
\hline $\begin{array}{l}\text { Respiratory therapy, body positioning, pain treatment, } \\
\text { drug- or fluid treatments, set up periphery line, rinsing the } \\
\text { catheter, assisting in the transfer of patients and treatment } \\
\text { of complications related to medical devices. }\end{array}$ & Nursing interventions 33 & \\
\hline Conversation, patient's supporting and guidance. & $\begin{array}{l}\text { Communication with the } \\
\text { patient } 20\end{array}$ & \\
\hline $\begin{array}{l}\text { Observe laboratory values or radiographies, previous } \\
\text { treatments and the treatment's limits. }\end{array}$ & Contributes to EMR 26 & \\
\hline $\begin{array}{l}\text { Staff guidance (monitoring of vital signs, diuresis and } \\
\text { body temperature, implementation of drug and fluid } \\
\text { treatments as well as respiratory and body positioning } \\
\text { therapies). }\end{array}$ & $\begin{array}{l}\text { Education on clinical } \\
\text { assessment } 20\end{array}$ & \multirow{3}{*}{ Indirect nursing $37 \%$} \\
\hline $\begin{array}{l}\text { MET call receiving and preparations of consultations, } \\
\text { evaluations of the results of the consultations, and } \\
\text { planning of control visits. }\end{array}$ & $\begin{array}{l}\text { MET work organisation } \\
36\end{array}$ & \\
\hline $\begin{array}{l}\text { Consultation with the doctor on call, anaesthetist and } \\
\text { nurse colleague. } \\
\text { Acted as a knowledge intermediary between nurse and } \\
\text { doctor. } \\
\text { Communication with nursing staff and support to the } \\
\text { alerting nurse. }\end{array}$ & $\begin{array}{l}\text { Multiprofessional } \\
\text { collaboration } 95\end{array}$ & \\
\hline
\end{tabular}


Table 6. Quotes from data

\begin{tabular}{|c|c|}
\hline Categories & Quotes from data \\
\hline \multicolumn{2}{|c|}{ Factors which induce nurses' concern } \\
\hline $\begin{array}{l}\text { Changes in the vital } \\
\text { signs }\end{array}$ & $\begin{array}{l}\text { - The breathing wheezes, use of accessory muscles to breathe (ACU nurse) (ACUn } \\
\text { 11) } \\
\text { - Hypotension. Vomited... Unwell and very weary woman... feverish... (ACUn 20) } \\
\text { - Pitting oedema in the legs. According to the patient, } 10 \text { kilograms over her usual } \\
\text { weight. At midnight, no urine in the bag (ACUn 2) } \\
\text { - Can be awakened, responds to questions with a few words, but falls asleep very easily } \\
\text { (ACUn 3) }\end{array}$ \\
\hline $\begin{array}{l}\text { Unexpected } \\
\text { trajectory }\end{array}$ & - In the dayroom, the vision went black... Did not faint (ACUn 28) \\
\hline $\begin{array}{l}\text { Patient's subjective } \\
\text { sensations }\end{array}$ & - A man who seemed tired. When asked, he claims to have pain... (ACUn 11) \\
\hline $\begin{array}{l}\text { Nurse's subjective } \\
\text { reasons for concern }\end{array}$ & $\begin{array}{l}\text { - Tired and exhausted man (ACUn 33) } \\
\text { - The RR level has risen, the patient's skin is cold and clammy, and the amount of } \\
\text { urine has decreased... (ACUn 11) } \\
\text { - Saturation levels decrease again, but it can be raised with an oxygen mask... The } \\
\text { MET nurse has been called. (ACUn 14) }\end{array}$ \\
\hline $\begin{array}{l}\text { Nurses' concern } \\
\text { associated with the } \\
\text { organisation of work }\end{array}$ & $\begin{array}{l}\text { - I called the MET as first aid, he can contact the ICU specialist if necessary (ACUn } \\
\text { 37) }\end{array}$ \\
\hline \multicolumn{2}{|c|}{ MET nurses' responses to the call } \\
\hline $\begin{array}{l}\text { The patient's } \\
\text { examination }\end{array}$ & $\begin{array}{l}\text { - Vitals ok, NEWS 3' (MET nurse) (METn 19) } \\
\text { - BP 107/81. The rhythm is uneven, atrial fibrillation. (METn 12) } \\
\text { - The status when meeting with... the awake patient. Calm, answers to the questions } \\
\text { with sense. (METn 1) } \\
\text { - The patient's pain was a few moments ago at its highest, a rank of } 10 \text { on the VAS } \\
\text { (METn 13) }\end{array}$ \\
\hline $\begin{array}{l}\text { Communicating with } \\
\text { the patient }\end{array}$ & $\begin{array}{l}\text { - He feels the same as yesterday... It is advised, that... would manage to be coming } \\
\text { up... He has been told as well, that rehabilitation is very important... He agreed. } \\
\text { (METn 37) }\end{array}$ \\
\hline $\begin{array}{l}\text { Contributing } \\
\text { EMRs }\end{array}$ & $\begin{array}{l}\text { - There is no more bleeding. Haemoglobin is stable. Labs have been checked. (METn } \\
\text { 24) }\end{array}$ \\
\hline $\begin{array}{l}\text { Nursing } \\
\text { interventions }\end{array}$ & $\begin{array}{l}\text { - } \quad \text { Breathing exercises, end up in an increase (METn 26) } \\
\text { - } \quad \text { The anaesthetist on call was consulted: the fresub dose is increased... (METn 27) }\end{array}$ \\
\hline Nursing staff guiding & $\begin{array}{l}\text { - Because of a confused condition and carbon dioxide retention, it was urged to abstain } \\
\text { from Oxanest... instructed to ask the treating doctor. (METn 7) }\end{array}$ \\
\hline $\begin{array}{l}\text { The organisation of } \\
\text { MET work }\end{array}$ & $\begin{array}{l}\text { - The alert is given by a nurse, worried about the patient's condition... (METn 6) } \\
\text { - The patient is conscious... Frantic... The patient stays under supervision, with that, } \\
\text { the situation calms down. (METn 31) } \\
\text { - MET visit in the morning and if needed earlier... (METn 31) }\end{array}$ \\
\hline $\begin{array}{l}\text { Multiprofessional } \\
\text { collaboration }\end{array}$ & $\begin{array}{l}\text { - The anaesthetist has been called about the patient's state and the nurse's wish, to } \\
\text { move the patient to the recovery room to monitoring... (METn 4) } \\
\text { - According to the nurses, when patient wakes up, he starts complaining about the } \\
\text { pain. (METn 7) } \\
\text { - The surgeon will come to see the patient, when he comes out the room. (METn 2) } \\
\text { - Instructed to easily contact the MET again, if the patient's state worsens. (METn 36) }\end{array}$ \\
\hline
\end{tabular}




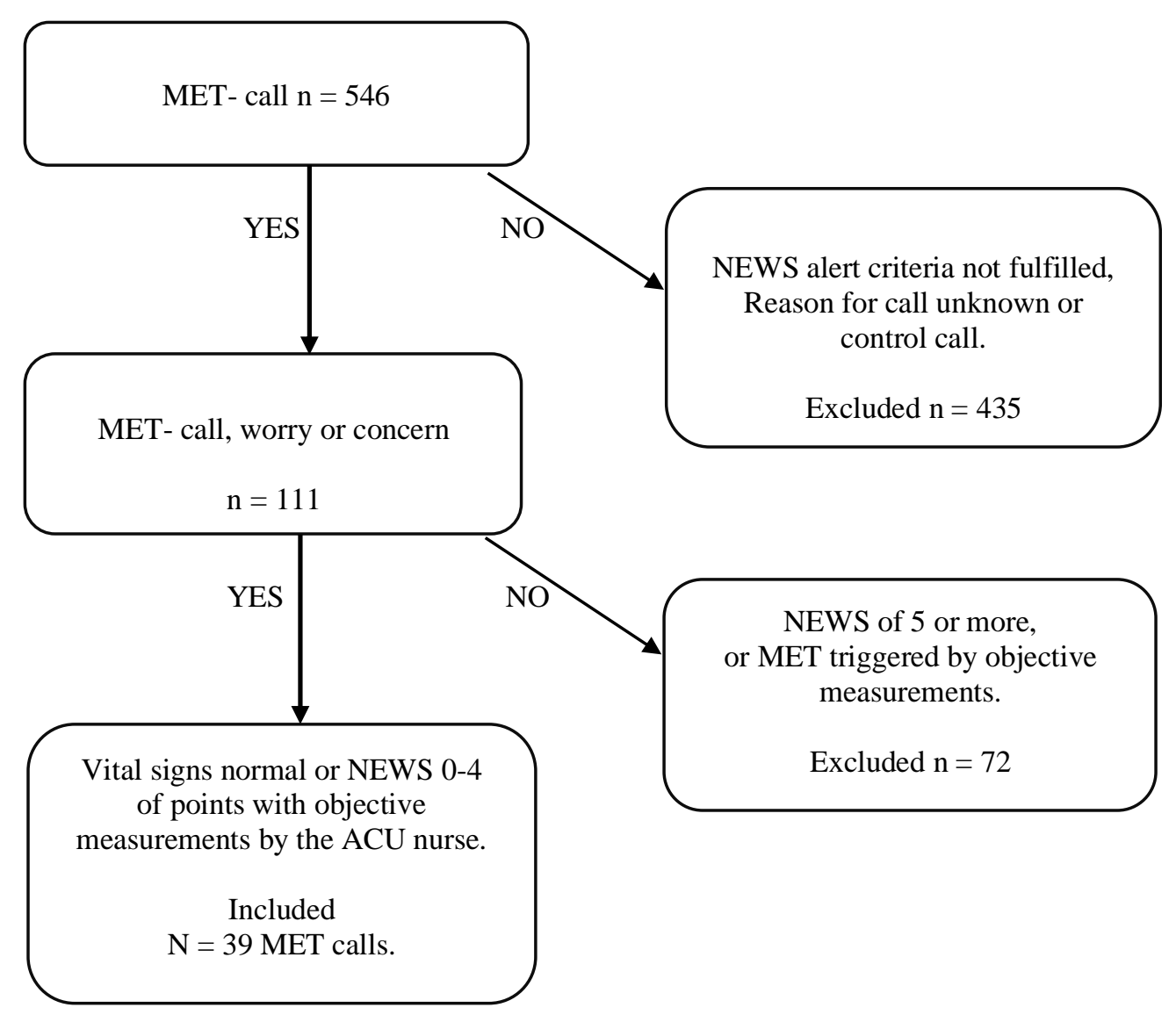

Figure 1. Description of the purposive sampling process, data from MET-forms and EMR

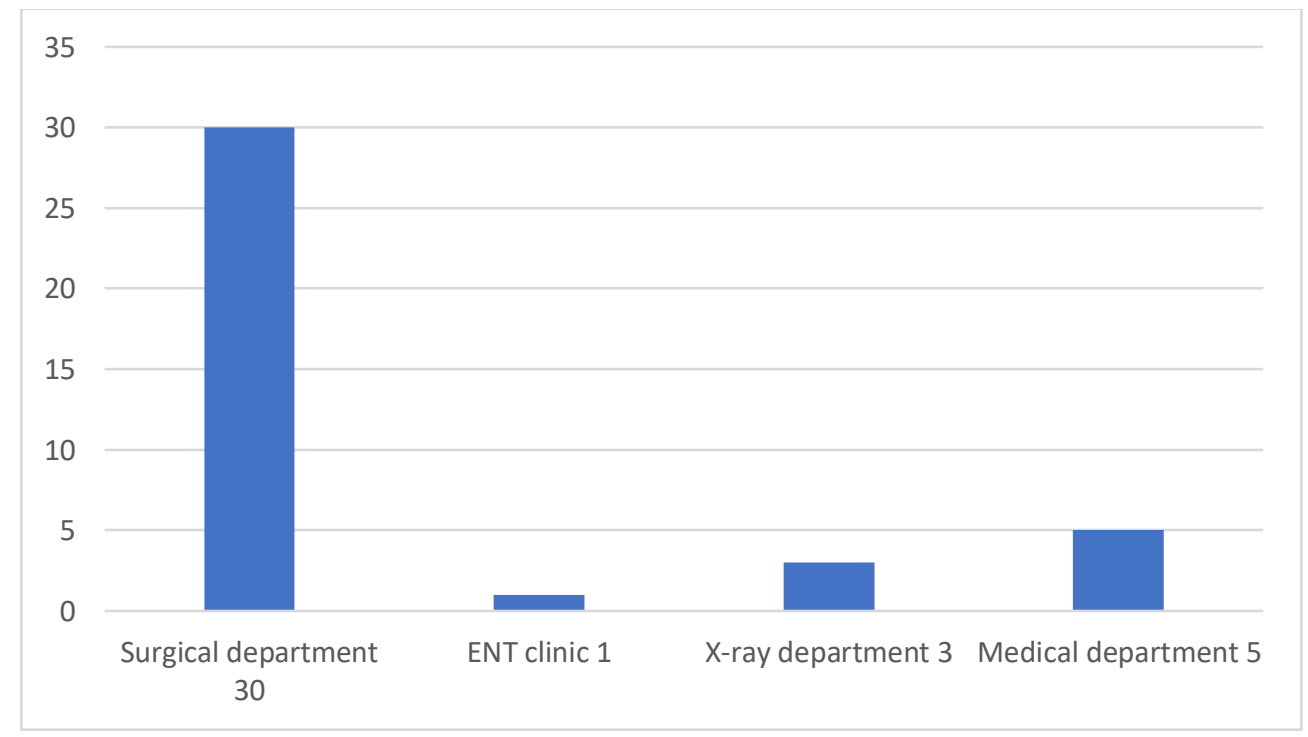

Figure 2. Origins of MET calls based on ward nurses' concern 